\title{
Migration forces of transcatheter aortic valves in patients with noncalcific aortic insufficiency
}

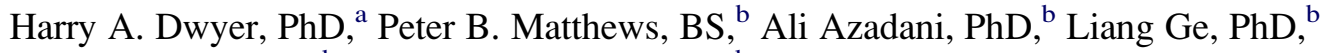 \\ T. Sloane Guy, MD, ${ }^{b}$ and Elaine E. Tseng, MD $^{\mathrm{b}}$
}

\begin{abstract}
Objective: Transcatheter aortic valves have been successfully implanted into the calcified leaflets of patients with severe aortic stenosis. However, their stability in patients with noncalcified aortic insufficiency is unknown. Similar to thoracic and abdominal aortic stent grafts, transcatheter aortic valves are subjected to antegrade ejection forces during systole. However, retrograde migration forces into the left ventricle are also generated by the diastolic pressure gradient across the closed valve. It has been suggested that leaflet calcification anchors the prosthesis, and measurements of migration forces should be considered before clinical trials in noncalcified aortic insufficiency. The objective of this study was to use computational fluid dynamics simulations to quantify forces that could potentially dislodge the prosthesis.
\end{abstract}

Methods: A computational fluid dynamics model was developed to simulate systolic flow through a geometric mesh of the aortic root and transcatheter aortic valves. Hemodynamic measurements were made at discrete moments during ejection. Unsteady control volume analysis was used for calculations of force on the mesh.

Results: Results of the simulation indicate that a total force of $0.602 \mathrm{~N}$ acts on the transcatheter aortic valves during systole, $99 \%$ of which is in the direction of axial flow. The largest contributor to force was the dynamic pressure gradient through the transcatheter aortic valves. This antegrade force is approximately 10 times smaller than the retrograde force $(6.01 \mathrm{~N})$ on the closed valve during diastole.

Conclusion: Our model simulated systolic flow through a transcatheter aortic valve and demonstrated migration into the left ventricle to be of greater concern than antegrade ejection.

Transcatheter aortic valves (TAVs) represent a minimally invasive treatment for degenerative aortic stenosis as an alternative to open aortic valve replacement. In this procedure, TAVs are implanted via a retrograde femoral arterial or antegrade transapical approach. The results have proven effective in relieving symptoms of aortic stenosis. However, no attempt has been made to use TAV as treatment for aortic insufficiency or other valvular disease not involving degenerative calcification of the cusps. Unlike traditional bioprostheses, which are sutured to the annulus, stent valves are not secured within the aorta. The forceful ejection of blood during systole could lead to stent dislodgement and antegrade migration distally into the arch or descending thoracic

From the Department of Mechanical and Aeronautic Engineering, University of California at Davis, ${ }^{\text {a }}$ Davis, Calif; and Department of Surgery, University of California at San Francisco Medical Center and San Francisco Veterans Affairs Medical Center, ${ }^{\text {b }}$ San Francisco, Calif.

Disclosures: This work was supported by the American Heart Association Beginning Grant-in-Aid 0565148Y (Burlingame, Calif) and the Northern California Institute for Research and Education (San Francisco, Calif). The authors have no financial conflicts of interest to disclose.

Received for publication Oct 27, 2008; revisions received Dec 23, 2008; accepted for publication Feb 1, 2009; available ahead of print Sept 15, 2009.

Address for reprints: Elaine E. Tseng, MD, UCSF Medical Center, Division of Cardiothoracic Surgery, 500 Parnassus Avenue, Suite W405, Box 0118, San Francisco, CA 94143-0118 (E-mail: elaine.tseng@ucsfmedctr.org).

J Thorac Cardiovasc Surg 2009;138:1227-33

$0022-5223 / \$ 36.00$

Copyright (c) 2009 by The American Association for Thoracic Surgery

doi:10.1016/j.jtcvs.2009.02.057 aorta. Such distal migration has been observed in some abdominal aortic stent grafts during long-term follow-up of abdominal aortic aneurysms. ${ }^{1}$ However, unlike abdominal stent grafts, TAVs are subjected to retrograde forces during diastole because of the pressure gradient across the closed valve. This force could lead to stent migration into the left ventricle. To the authors' knowledge, no computational simulations have modeled TAV hemodynamics. This study seeks to use computational fluid dynamics (CFD) to investigate flow, wall shear stress, and total force acting on the device to assess TAV migration in noncalcific aortic insufficiency.

\section{MATERIALS AND METHODS}

\section{Transcatheter Aortic Valve Geometry and}

\section{Simulation}

A 3-dimensional geometric model or mesh was generated, extending from the aortic annulus to the proximal descending thoracic aorta. The region to be studied in the greatest detail, the aortic root, contains geometry of the aortic sinuses developed from anatomic measurements available in literature. ${ }^{2,3}$ The ascending aorta and arch are modeled as a simple curved pipe, excluding the arterial branches. A second mesh was generated of the TAV and merged with the aortic mesh at the annulus. Assumptions were made about the geometry of the TAV for the sake of simplicity. The simulation represents TAV implantation within an incompetent valve, as opposed to a calcified, stenotic valve, and the native leaflets are presumed to have a negligible effect on flow. The TAV and annulus are circular and contiguous, allowing no paravalvular leak into the left ventricle. Second, the TAV mesh does not include the stainless steel or nitinol frame of the stent. When fully opened, the cusps of the TAV are flush with the frame and take 


\section{Abbreviations and Acronyms \\ $\mathrm{CFD}=$ computational fluid dynamics \\ $\mathrm{TAV}=$ transcatheter aortic valve}

$$
\begin{gathered}
p=\frac{p_{\text {dyanic }}}{\rho\left(\frac{(\max }{2}\right)^{2}} \tau=\frac{\tau_{\text {real }}}{\mu_{\text {Dimax }}^{\text {Diameler }}} \\
\text { And } \rho\left(\frac{U_{\max }}{2}\right)^{2}=90 \mathrm{~Pa} \text { and } \mu \frac{U_{\max }}{\text { Diameter }}=0.084 \mathrm{~Pa}
\end{gathered}
$$

the shape of the stent housing (Figure 1, A). An open cylinder was used to model this geometry; the cusps are not attached at the commissures and do not intrude into the sinus cavity (Figure 1, $B$ ).

This study models approximately $300 \mathrm{msec}$ of systolic flow. Although in vivo, the opening of the TAV takes place over a finite time, the precise kinematics of the opening and closing of the cusps during this period are not simulated. As such, unsteady flow from the left ventricle is assumed to begin after instantaneous TAV opening, ignoring flow during the short period when the valve is partially opened. Throughout the simulation of systole the cusps remain static and fully open, fixed within the stent. The loading conditions driving flow through the mesh were taken from the literature and are representative of normal systolic pressures. ${ }^{4}$ CFD simulations are performed to study flows through the rigid mesh; aortic root dilation is not modeled.

\section{Computational Fluid Dynamics}

The CFD methodology used in this study has previously proven its efficacy characterizing flow in the aortic arch and bifurcations. ${ }^{4,5}$ This approach requires a detailed 3-dimensional and time-dependent description of flow through the aortic valve. The simulation is driven by a system of fluid flow equations, Navier-Stokes, which for an incompressible fluid in dimensionless control volume form are as follows:

$$
\begin{aligned}
& \iint_{S} \vec{V} \bullet d \vec{A}=0 \quad \text { Continuity } \\
& \frac{\alpha^{2}}{\operatorname{Re}} \iiint_{V} \frac{\partial \vec{V}}{\partial t} d V+\iiint_{V}(\vec{V} \bullet \vec{V}) \vec{V} d V=-\iint_{S} p \bullet d \vec{A} \\
& +\frac{1}{\operatorname{Re}} \iint_{S} \overline{\bar{\tau}} \bullet d \vec{A} \text { Momentum }
\end{aligned}
$$

where $\mathrm{p}$ is the pressure, $\overline{\bar{\tau}}$ is the viscous stress tensor, $\operatorname{Re}=\frac{2 R \bar{U}}{\nu}$ is the Reynolds Number, $\alpha=R\left(\frac{\omega}{v}\right)^{1 / 2}$ is the Womersley parameter, $\mathrm{R}$ is the inlet radius of the aorta, $\bar{U}$ is the maximum inlet velocity, $\nu$ is the kinematic viscosity of the fluid, and $\omega$ is the inlet pulse frequency ( $\omega=2 \pi \mathrm{f}$ where $\mathrm{f}$ is the heart rate). Blood flowing through the aorta is modeled as a Newtonian fluid, appropriate for CFD simulations of arterial flow. ${ }^{6}$ Computational evaluations are made for discrete time intervals at a rate of 320 computational steps per second. Values for the maximum velocity and flow area are used as reference to nondimensionalize computations, allowing good estimation to be made over a significant Reynolds number and size range. These values are as follows:

$$
U_{\max }=60 \mathrm{~cm} / \mathrm{sec} A_{\text {flow }}=\pi r^{2} \quad r=1.2 \mathrm{~cm} A_{\text {flow }}=4.52 \times 10^{-4} \mathrm{~m}^{2}
$$

The total force on the aortic valve is obtained by performing an unsteady control volume force analysis, and the control volume is defined by the mesh that surrounds the valve and the meshes across the inlet and exit areas of the valve. ${ }^{7}$ There are 4 contributions to the force: (1) the fluid momentum flux at the inlet and exit of the valve; (2) the unsteady change of momentum in the valve control volume; (3) the dynamic pressure force on the valve; and (4) the viscous shear stresses on the outer wall of the valve.

The dimensionless force coefficient, $C_{\text {force }}$, is defined as follows:

$$
C_{\text {force }}=\frac{\text { Force }_{\text {real }}}{\rho U_{\max }^{2} A_{\text {flow }}} \text { where } \rho-\text { fluid density } U_{\max }-\text { Maximum flow velocity }
$$

The values of pressure and shear stress in the figures have also been made dimensionless in the following manner:

\section{RESULTS}

\section{Flow Through the Transcatheter Aortic Valve}

The results of the simulation are presented first with velocity vectors and dynamic pressure contours (Figure 2). It should be mentioned that the dynamic pressure field is not the blood pressure, but rather it is determined from the local spatial gradient of the blood pressure caused by the flow. Velocity fields in the aortic arch and at points distal are essentially identical to those seen in unsteady flow analysis through a simple curved pipe, suggesting that implantation of the TAV has a negligible effect on hemodynamics downstream of the ascending aorta. ${ }^{8}$ Control of flow in the arch is dominated by the Womersley parameter, which is sensitive to changes in heart rate, as opposed to the geometry.

Unlike the flow seen in the aortic arch, the TAV alters hemodynamics in the root and ascending aorta considerably (Figure 3). Flow in the center of the aortic lumen continues to converge and accelerate after the valve. However, average velocity across the entire vessel decreases distal to the valve because of the increase in lumen area. If the leaflets remain fully open during ejection and the wall motion is neglected, the net fluid that flows in and out of the sinus cavity must be equal because of conservation of mass. Unsteady flow into and out of the sinus region is due to non-uniform fluid entrainment locally at the valve tip. The value of unitless flow presented in the figure is the axial component of flow, and the sinus bulge creates the movement of blood in both the positive and negative direction, as well as rotational flow around the leaflet. The geometric cause of the unsteady sinus flows is the non-axisymmetric shape of the sinus cavity, which influences the interaction with the flow in the valve.

\section{Forces on the Transcatheter Aortic Valve}

Throughout ejection, the largest component of force is pressure (Figure 4), followed by momentum flux force. Both the viscous force on the outside of the valve and unsteady flow forces in the valve are less than a few percent of the total force. Total force on the TAV is the magnitude or absolute value of the components of force in all 3 dimensions. However, approximately $99 \%$ of the total force is in the direction of axial flow. Total force peaks during maximum systolic flow at 0.602 Newtons. The pressure field observed corresponds with previous simulations and is dominated by the unsteady frequency parameter, $\alpha$, in the large arteries. 8,9 


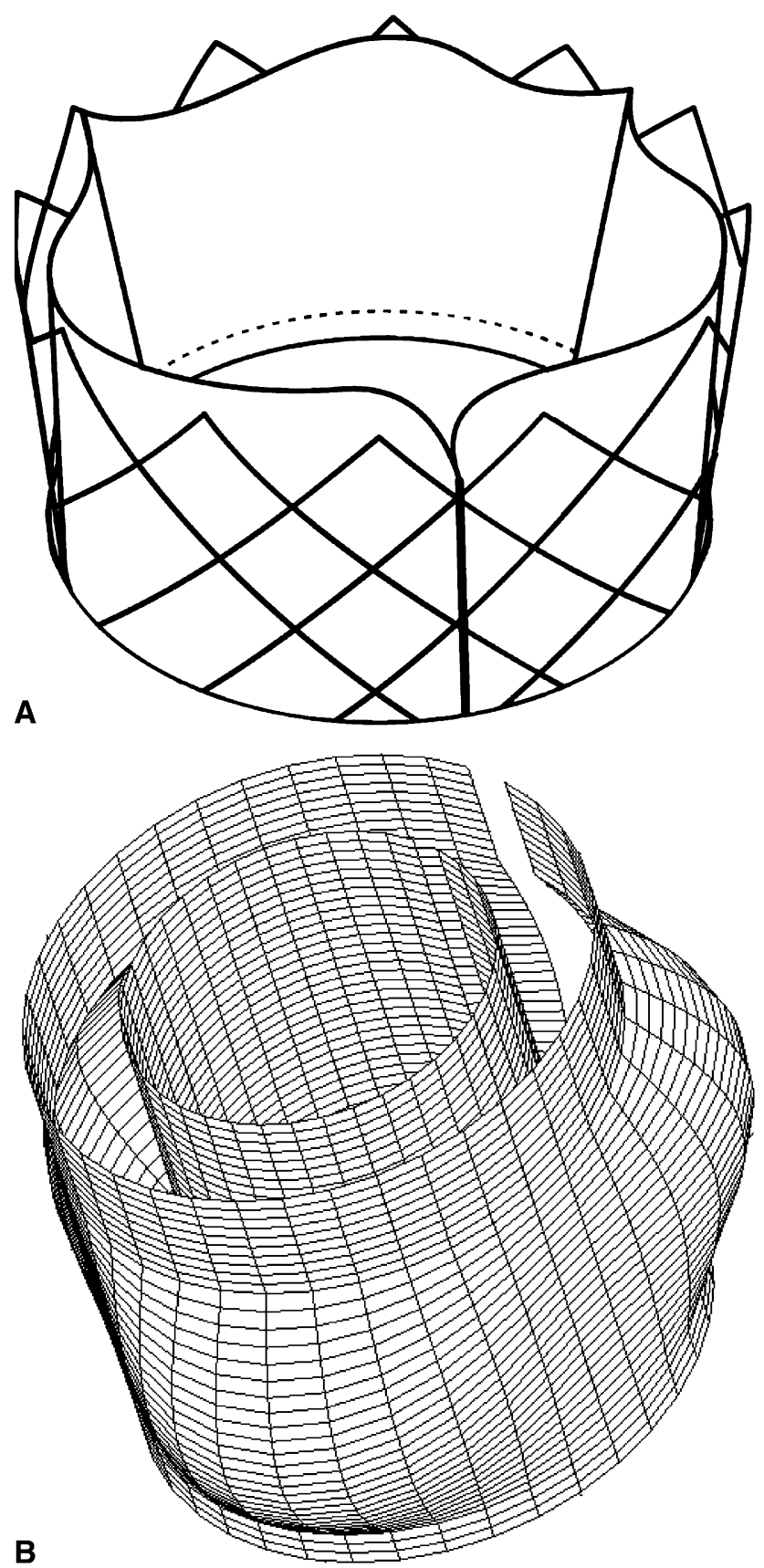

FIGURE 1. TAV schematics. A, Schematic of an open TAV. B, Surface mesh of the TAV within the aortic root. TAV, Transcatheter aortic valve.

\section{Wall Shear Stress}

Figure 5 shows the magnitude or absolute value of the total wall shear stress on the ventricular TAV leaflet surfaces and the sinus surface. Shear stress on the TAV is larger than on the sinuses on average; however, at locations near the valve tip the sinus wall shear stress can approach more than $50 \%$ of valve wall shear stresses. At all times in the simulation, the maximum shear stress on the aortic sinus wall is located just distal to the bulge region of the sinus
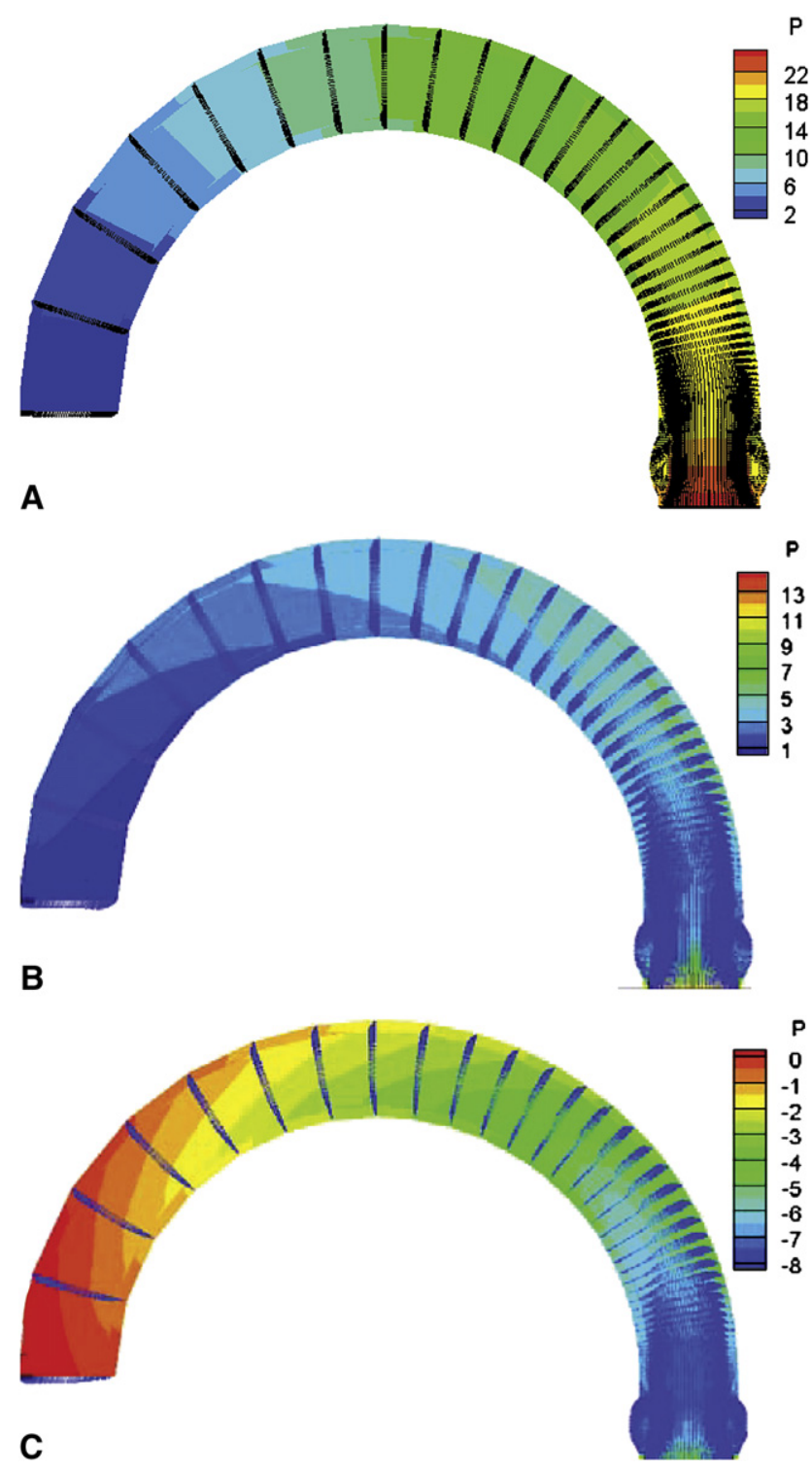

FIGURE 2. Velocity vectors and dynamic pressure contours in the aortic arch. A, Maximum flow acceleration. B, Maximum flow. C, Maximum flow deceleration.

where the diameter is greatest. It seems that dynamic fluid entrainment caused by the sinus influences this profile of wall shear stress.

The greatest shear stress on the TAV occurs near the tip of the leaflets and peaks during maximum flow through the valve, corresponding to previous studies of shear in both the root and the aortic arch. ${ }^{4}$ Maximum shear stress on the valve leaflet tips is approximately $40 \mathrm{~Pa}$ (Equation 5).

\section{Diastolic Force: Engineering Estimates}

Considerable antegrade force acts on the TAV during ejection, pushing the prosthesis along the axis of flow. To determine the significance of this force, the entire cardiac cycle should be taken into consideration. At the beginning 


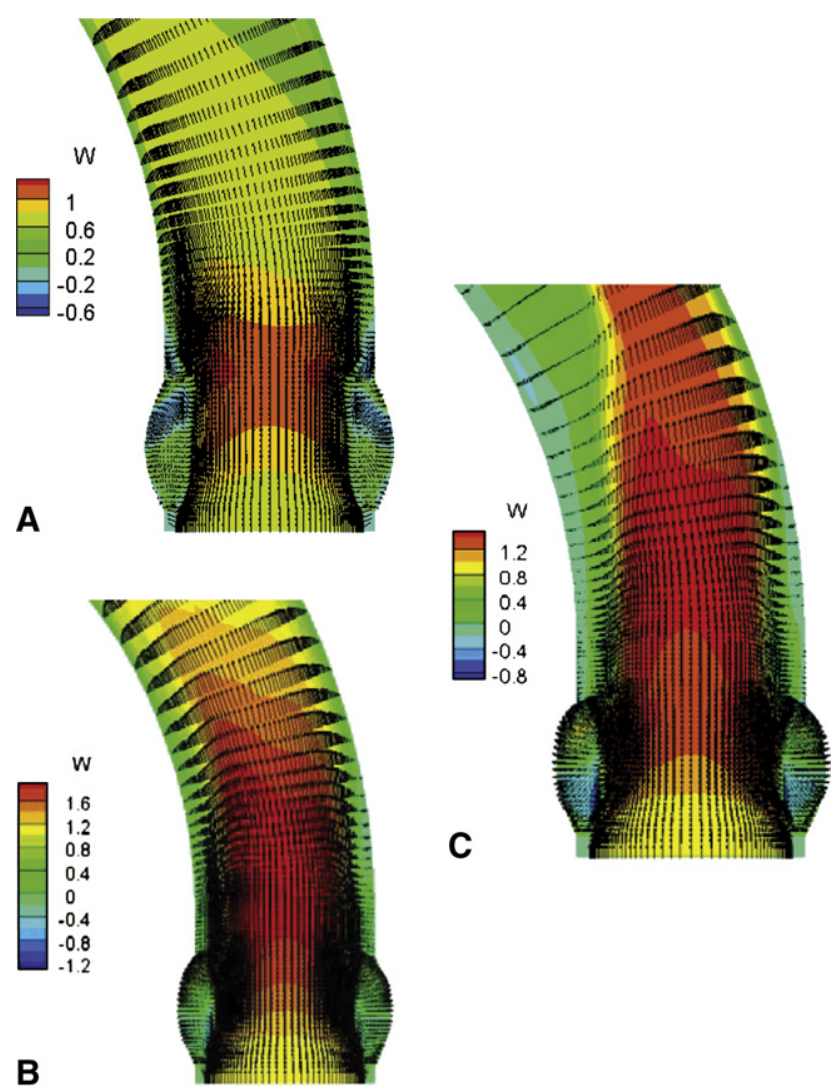

FIGURE 3. Velocity profile with velocity contours in the aortic root. A, Maximum flow acceleration. B, Maximum flow. C, Maximum flow deceleration.

of diastole, a small retrograde flow occurs during valve closure but likely generates negligible force. During left ventricular relaxation, however, the closed TAV is subjected to a large retrograde pressure gradient. A simple approximation can be made to estimate the resulting force on the TAV using left ventricular and ascending aortic pressure. The net pressure force occurs along the axis of flow and depends only on the projected area in that direction, as defined by the valve radius $r_{\text {valve }}$ at the annulus. Considering the same size TAV used in the CFD simulation, area and force are:

$$
\begin{gathered}
r_{\text {valve }}=12 \mathrm{~mm} A_{\text {projected }}=\pi r_{\text {valve }}^{2}=4.52 \mathrm{~cm}^{2} \\
\text { Force }=\Delta p_{\text {valve }} A_{\text {projected }}=6.01 \mathrm{~N}=1.36 \mathrm{lb}_{f}
\end{gathered}
$$

Peak force during diastole is approximately an order of magnitude greater than peak force during systole.

\section{DISCUSSION}

CFD simulations in this study characterize for the first time flow though TAV and quantify the hemodynamics from the annulus to the descending aorta. Jet flow through the TAV leads to flow in the center of the lumen, converging distal

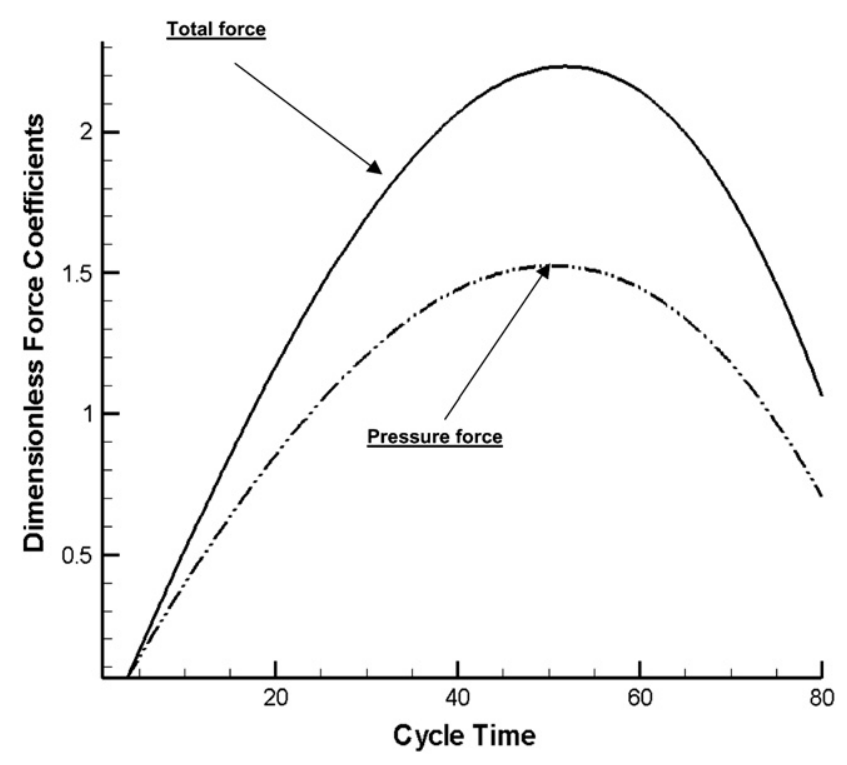

FIGURE 4. Force on the TAV. Magnitude of total force and pressure, the largest contributing component, during systole. Force and time are presented in dimensionless units from the simulation.

to the valve. A peak force of $0.602 \mathrm{~N}$ is exerted on the TAV, approximately $99 \%$ of which is in the direction of axial flow. The leaflet tips are subjected to a wall shear stress of approximately $40 \mathrm{~Pa}$. Finally, a simple engineering estimate shows total force during diastole to be $6.01 \mathrm{~N}$, approximately 10 times larger than force during ejection through the TAV.

\section{Implantation of Transcatheter Aortic Valves}

The first human percutaneous TAV implantation was performed in 2002 by Alain Cribier and colleagues. ${ }^{10}$ Overall, TAV has $73 \%$ to $100 \%$ implant success and procedural mortality of $2 \%$ to $14 \%$ in patients with predicted surgical mortalities of $12 \%$ to $31 \%$. Surgical conversion was $0 \%$ to $2 \%$, periprocedural stroke occurred in $0 \%$ to $10 \%$, and 30 -day mortality was $12 \%$ to $22 \% .^{10-19}$ Hemodynamically successful treatment of calcified aortic stenosis was achieved without major complications. Valve area significantly improved $\left(0.5-0.7\right.$ to $\left.1.5-1.7 \mathrm{~cm}^{2}\right)$; transvalvular gradients substantially decreased (32-46 $\mathrm{mm} \mathrm{Hg}$ to $9-11 \mathrm{~mm} \mathrm{Hg}$ ); and ejection fraction increased $(45 \%-53 \%$ to $53 \%-$ $60 \%$ ). However, TAV implantation has never been attempted for treatment of aortic insufficiency in humans. Structural differences between a calcified, stenotic aortic valve and a dilated or prolapsing incompetent valve are significant. Patients requiring ascending aortic replacement or valve-sparing aortic root replacement to treat aortic insufficiency would not seem to be good candidates for TAV. Although the proportion of patients with isolated aortic insufficiency may not be substantial, once TAV technology becomes Food and Drug Administration approved, off-label use of TAV may potentially be expanded to patients without 


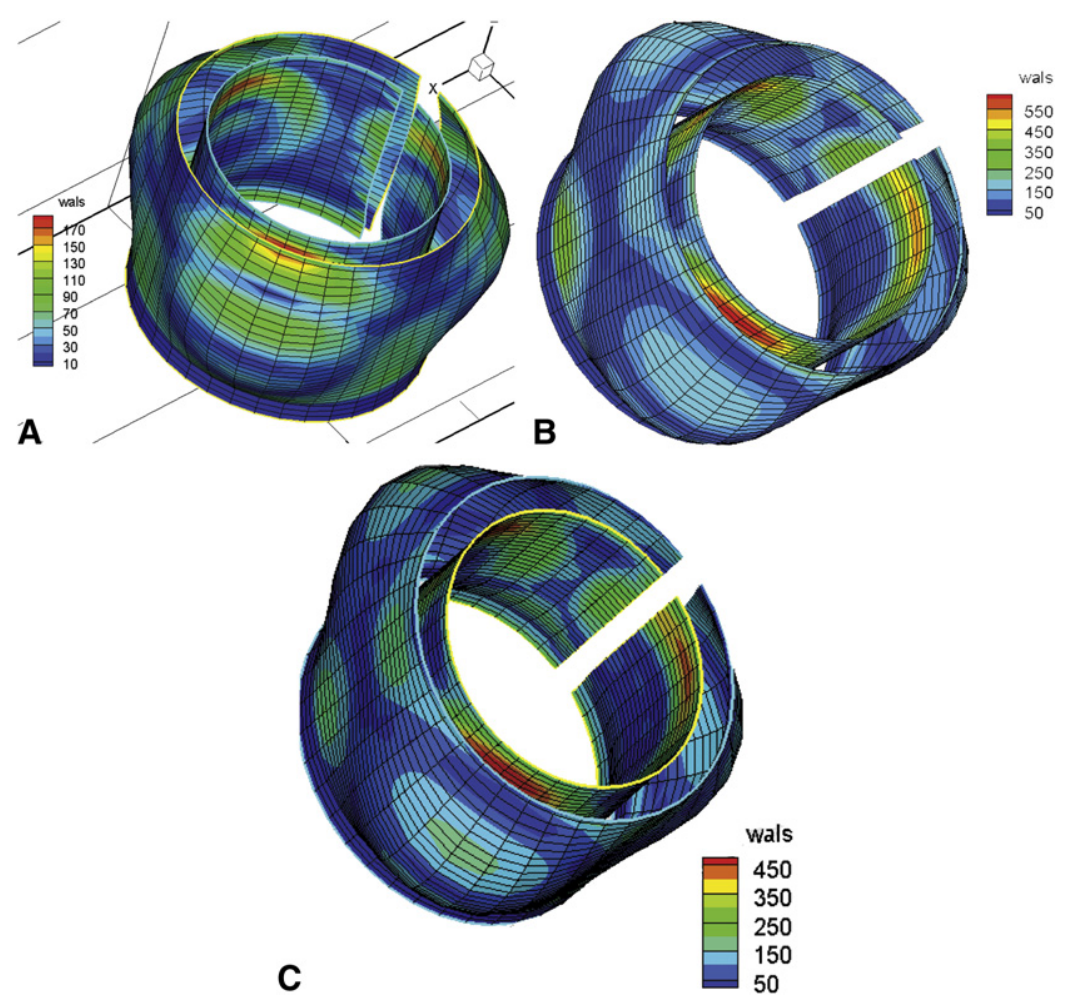

FIGURE 5. Contours of wall shear stress on the transcatheter aortic valve and aortic root. A, Maximum flow acceleration. B, Maximum flow. C, Maximum flow deceleration.

significant calcification. Before consideration for clinical use, computational and experimental studies should be conducted to evaluate the safety of TAV under this pathology.

\section{Predicting Stent Migration}

Clinically, TAVs rarely migrate when seated correctly, despite large shear forces during systole and pressure gradients during diastole. One hypothesis is that calcification of the native leaflets anchors the stent in place because of a reduction in annular pliability. ${ }^{20}$ Should this hypothesis be true, treatment of aortic insufficiency with TAV is likely not advisable. In Cribier's early experience of percutaneous treatment for severe aortic stenosis, 1 of the 6 enrolled patients died as a result of TAV migration. ${ }^{13}$ This patient had a highly irregular valve, with 1 leaflet torn away from the annulus during preTAV aortic balloon valvuloplasty, which resulted in massive aortic insufficiency. Because of the anatomy, the TAV was deployed but ejected distally during full balloon inflation, which the investigators believe led to its migration because of the absence of calcium for stent valve fixation.

Aortic stenosis cannot be readily re-created in an animal model, and thus in vivo animal studies more accurately simulate aortic insufficiency than stenosis. During a 2006 study of TAV implantation in pigs, 8 of 26 valves migrated ( 2 distal, 6 retrograde). ${ }^{21}$ Of these, 5 valves were cited to migrate into the left ventricle after a normal implantation when the pig was weaned from cardiopulmonary bypass or rapid ventricular pacing. Another investigation of TAV deployment within pigs reported that $40 \%$ of the prostheses migrated shortly after being seated (6/15 total; 3 distal, 3 retrograde migrations). ${ }^{20}$ The investigator cited the size and compliance of the normal, noncalcified root as a possible explanation for the dislodgement of the prosthesis. In light of these experimental results, patients with pure aortic insufficiency could present the same risk of migration, and additional means should be taken to secure the stent.

\section{Securing the Stent}

Migration is a known complication of all stent grafts but a clinical hazard and potential source of mortality for TAVs. Mechanically, migration is a device failure created when forces acting on the stent overcome the strength of the stent's attachment to the vessel wall. Studies using static pressurization of abdominal aortic stent grafts within cadaver and animal models have been used to quantify the force necessary for migration. Drag force, which holds the stent in place, is highly dependent on the outer surface of the device: 2 to $4 \mathrm{~N}$ for smooth stents and 7 to $12 \mathrm{~N}$ for stents with hooks and barbs. ${ }^{22}$ Newer designs have drag forces measured up to $25 \mathrm{~N}^{23}$ When implanting a self-expanding TAV in an animal model, both antegrade and retrograde migrations were problematic. ${ }^{24}$ Initially, migration into the left 
ventricle occurred during deployment, requiring the addition of retaining hooks to the design. In subsequent trials, the stent migrated antegrade after a successful deployment. Retaining hooks were added to prevent early retrograde migration, and increasing the radial force of the stent wire and oversizing the TAV were necessary to prevent migration into the ascending aorta.

\section{Study Limitations}

The simulation results were generated using a simplified, although physically reasonable, model of an implanted TAV during systole. For the purpose of comparison, we have made an engineering estimate of the closed TAV during diastole. A comprehensive study, incorporating the surface of the closed leaflets and the dynamic pressures in the aorta and left ventricle, is necessary for a more accurate prediction of diastolic force. As stated previously, this simulation does not model leaflet kinematics. The results show that peak shear stress and total force on the TAV both occur at maximum flow, indicating that the short period while leaflets are still opening is unimportant for TAV failure. The kinematics, however, are necessary to predict fatigue and long-term degeneration resulting from leaflet bending. ${ }^{25}$ CFD simulation can calculate shear stress on TAV leaflets in detail that would be extremely difficult or impossible to determine experimentally. Nonetheless, future experimental and clinical investigation are necessary to validate the results. Last, the compliance of the aortic root and TAV is not incorporated in the model. We demonstrate that as blood exits the left ventricle during systole, it interacts with the distal edge of the TAV, and fluid entrainment creates complex vortical flow in the sinus cavity. Blood leaving the sinus along the aortic face of the TAV leaflet pulls new blood into the sinus from near the aortic root wall, creating regions of both positive and negative axial flow. Eddy currents and turbulence may be created in this region by interaction of the fluid at the boundaries of the TAV and the compliant aortic root. Realistic simulation of these complex phenomena requires the addition of fluid-structure interaction to the model, which may be performed in future studies.

\section{CONCLUSIONS}

CFD simulations in this study provide the first of its kind data quantifying hemodynamics of TAV within an incompetent aortic valve. The proposed treatment has not been attempted clinically and has shown only limited success in animals. Total force, likely the most significant result of this study, indicates that antegrade migration of TAV may not be a concern because it is in abdominal aortic stent grafts, when compared with retrograde migration. However, the drag force acting to prevent migration is unknown and possibly dependent on the direction of migration because of the irregular geometry.
Overall, CFD models are useful to investigate how a change in geometry leads to a change in hemodynamics. If the change is significant, a complete fluid-structure interaction model should be developed to investigate the deformation of the aortic root as well, and ultimately to estimate the drag force necessary to prevent stent migration. The TAV-root surface interaction will be the dominating parameter of drag, and a reliable model for testing specific surface geometries of both has 2 benefits. First, future TAV designs could be developed with anchoring elements, such as the hooks and barbs of abdominal aortic stents, to increase drag. Second, patients with certain valve disease, such as noncalcified incompetent leaflets, could be screened to predict whether TAV implantation is safe. These 2 benefits may lead to greater surgical success or an inclusion of patients not currently considered for TAV.

\section{References}

1. Lee WA. Infrarenal aortic devices: failure modes and unmet needs. Semin Vasc Surg. 2007;20:75-80.

2. De Hart J, Peters GW, Schreurs PJ, Baaijens FP. Collagen fibers reduce stresses and stabilize motion of aortic valve leaflets during systole. J Biomech. 2004;37: 303-11.

3. De Hart J, Cacciola G, Schreurs PJ, Peters GW. A three-dimensional analysis of a fibre-reinforced aortic valve prosthesis. J Biomech. 1998;31:629-38.

4. Shahcheraghi N, Dwyer HA, Cheer AY, Barakat AI, Rutaganira T. Unsteady and three-dimensional simulation of blood flow in the human aortic arch. J Biomech Eng. 2002;124:378-87.

5. Kim T, Cheer AY, Dwyer HA. A simulated dye method for flow visualization with a computational model for blood flow. J Biomech. 2004;37:1125-36.

6. Berger SA, Goldsmith EW, Lewis ER. Introduction to Bioengineering. Oxford, UK: Oxford University Press; 2000.

7. White FM. Viscous Fluid Flow. 2nd. New York: McGraw-Hill; 1991.

8. Dwyer HA, Cheer AY, Rutaganira T, Shahcheraghi N. Calculation of unsteady flows in curved pipes. J Fluids Eng. 2001;123:869-77.

9. Pedley TJ. The Fluid Mechanics of Large Blood Vessels. Cambridge, UK: Cambridge University Press; 1980.

10. Cribier A, Eltchaninoff H, Bash A, Borenstein N, Tron C, Bauer F, et al. Percutaneous transcatheter implantation of an aortic valve prosthesis for calcific aortic stenosis: first human case description. Circulation. 2002;106:3006-8.

11. Bauer F, Eltchaninoff H, Tron C, Lesault PF, Agatiello C, Nercolini D, et al. Acute improvement in global and regional left ventricular systolic function after percutaneous heart valve implantation in patients with symptomatic aortic stenosis. Circulation. 2004;110:1473-6.

12. Cribier A, Eltchaninoff H, Tron C, Bauer F, Agatiello C, Nercolini D, et al. Treatment of calcific aortic stenosis with the percutaneous heart valve: mid-term follow-up from the initial feasibility studies: the French experience. $J$ Am Coll Cardiol. 2006;47:1214-23.

13. Cribier A, Eltchaninoff H, Tron C, Bauer F, Agatiello C, Sebagh L, et al. Early experience with percutaneous transcatheter implantation of heart valve prosthesis for the treatment of end-stage inoperable patients with calcific aortic stenosis. $J$ Am Coll Cardiol. 2004;43:698-703.

14. Grube E, Laborde JC, Gerckens U, Felderhoff T, Sauren B, Buellesfeld L, et al. Percutaneous implantation of the CoreValve self-expanding valve prosthesis in high-risk patients with aortic valve disease: the Siegburg first-in-man study. Circulation. 2006;114:1616-24.

15. Grube E, Schuler G, Buellesfeld L, Gerckens U, Linke A, Wenaweser P, et al. Percutaneous aortic valve replacement for severe aortic stenosis in high-risk patients using the second- and current third-generation self-expanding CoreValve prosthesis: device success and 30-day clinical outcome.J Am Coll Cardiol. 2007;50:69-76.

16. Lichtenstein SV, Cheung A, Ye J, Thompson CR, Carere RG, Pasupati S, et al. Transapical transcatheter aortic valve implantation in humans: initial clinical experience. Circulation. 2006;114:591-6.

17. Webb JG, Chandavimol M, Thompson CR, Ricci DR, Carere RG, Munt BI, et al. Percutaneous aortic valve implantation retrograde from the femoral artery. Circulation. 2006;113:842-50 
18. Webb JG, Pasupati S, Humphries K, Thompson C, Altwegg L, Moss R, et al. Percutaneous transarterial aortic valve replacement in selected high-risk patients with aortic stenosis. Circulation. 2007;116:755-63.

19. Ye J, Cheung A, Lichtenstein SV, Pasupati S, Carere RG, Thompson CR, et al. Six-month outcome of transapical transcatheter aortic valve implantation in the initial seven patients. Eur J Cardiothorac Surg. 2007;31:16-21.

20. Walther T, Dewey T, Wimmer-Greinecker G, Doss M, Hambrecht R, Schuler G, et al. Transapical approach for sutureless stent-fixed aortic valve implantation: experimental results. Eur J Cardiothorac Surg. 2006;29:703-8.

21. Dewey TM, Walther T, Doss M, Brown D, Ryan WH, Svensson L, et al. Transapical aortic valve implantation: an animal feasibility study. Ann Thorac Surg. 2006;82:110-6.
22. Morris L, Delassus P, Walsh M, McGloughlin T. A mathematical model to predict the in vivo pulsatile drag forces acting on bifurcated stent grafts used in endovascular treatment of abdominal aortic aneurysms (AAA). J Biomech. 2004;37:1087-95.

23. Li Z, Kleinstreuer C. Analysis of biomechanical factors affecting stent-graft migration in an abdominal aortic aneurysm model. J Biomech. 2006;39: 2264-73.

24. Laborde JC, Borenstein N, Behr L, Farah B, Fajadet J. Percutaneous implantation of an aortic valve prosthesis. Catheter Cardiovasc Interv. 2005;65:171-5.

25. Kim H, Lu J, Sacks MS, Chandran KB. Dynamic simulation of bioprosthetic heart valves using a stress resultant shell model. Ann Biomed Eng. 2008;36:262-75. 